\title{
Flowers of European pear release common and uncommon volatiles that can be detected by honey bee pollinators
}

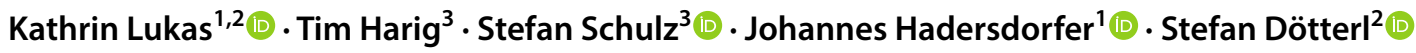

Received: 9 July 2019 / Accepted: 16 October 2019 / Published online: 2 November 2019

(c) The Author(s) 2019

\begin{abstract}
Floral scents are important pollinator attractants, but there is limited knowledge about the importance of single components in plant-pollinator interactions. This especially is true in crop pollination systems. The aim of this study is to identify floral volatiles of several European pear cultivars (Pyrus communis L.), and to determine their potential in eliciting physiological responses in antennae of honey bees (Apis mellifera L.), the most important pollinators of pear. Volatiles were collected by dynamic headspace and analysed by (high resolution) gas chromatography coupled to mass spectrometry (GC/MS) and nuclear magnetic resonance spectroscopy. Antennal responses were investigated by GC coupled to electroantennographic detection (GC/EAD). We trapped in the mean $256 \mathrm{ng}$ of scent per flower and hour (flower ${ }^{-1} \mathrm{~h}^{-1}$ ) from the different cultivars with either linalool + methyl benzoate or methyl 2-hydroxy-3-methylpentanoate as most abundant compounds. Of the 108 detected pear floral scent components, 17 were electrophysiologically active in honey bee antennae. Among these compounds were (E)-N-(2-methylbutyl)- and (E)-N-(3-methylbutyl)-1-(pyridin-3-yl)methanimine, which were not known from nature before to the best of our knowledge. Most other compounds identified as flower scent in pear are widespread compounds, known from flowers of various other species. Our results provide new insights in the floral volatile chemistry of an important insect-pollinated crop and show for the first time that honey bees have the olfactory ability to detect several pear floral volatiles. These data are an important basis for more detailed studies of the olfactory communication between honey bees and European pear flowers and might in the long term be used to manipulate the attractiveness of pear to obtain optimal fruit set.
\end{abstract}

Keywords Apis mellifera L. · Crop pollination · Electrophysiological analysis · Insect-plant interaction · Pyrus communis L. Floral scent

\section{Introduction}

Pollination by animals is one of the most important ecosystem services (Ollerton et al. 2011), as not only wild plants but also agricultural crops benefit from animal pollination (McGregor 1976; Free 1993; Williams 1994 in Klein et al. 2007; Delaplane et al. 2000; Khan and Khan 2004; Klein

Handling Editor: Marko Rohlfs.

Stefan Dötterl

Stefan.Doetterl@sbg.ac.at

1 Associate Professorship of Fruit Science, Technical University of Munich, Dürnast 2, 85354 Freising, Germany

2 Department of Biosciences, Paris-Lodron-University of Salzburg, Hellbrunner Str. 34, 5020 Salzburg, Austria

3 Institute of Organic Chemistry, Technische Universität Braunschweig, Hagenring 30, 38106 Brunswick, Germany et al. 2007). Klein et al. (2007) described an increase in yield for 39 crops due to animal pollination, which overall is responsible for an estimated $35 \%$ of global food production. The most important pollinators of fruit crops are social honey bees (McGregor 1976; Free 1993; Delaplane et al. 2000). Nonetheless, the contribution of bumble bees (Shipp et al. 1994; Dogterom et al. 1998; Dag et al. 2006) and other wild bees to the pollination of crops is substantial as well (Free 1993; Maccagnani et al. 2003; Monzón et al. 2004; Holzschuh et al. 2012; Rader et al. 2016).

Although pollinators are typically attracted to flowers by visual and olfactory cues (Bogdany and Taber 1979; De Jong and Pham-Delègue 1991; Dobson et al. 1999; Burger et al. 2010; Dötterl et al. 2011), with the relative importance of the cues varying among pollination systems (Ômura and Honda 2005; Balkenius et al. 2006; Dötterl et al. 2011), there is limited knowledge about the detailed communication between flowers of fruit crops and their pollinators. For 
a few fruit crops, however, it was just recently demonstrated that the main floral scent constituents are capable of attracting pollinators when offered as single synthetic compounds or synthetic mixtures (e.g., Cordeiro et al. 2017; El-Sayed et al. 2018; Krug et al. 2018). Compounds involved in such interactions are, among others, a mixture of benzyl alcohol, 2-phenylethanol, hexanal, 1-hexanol, (Z)-3-hexen-1-ol, and 1-octanol in cambuci plants (Campomanesia phaea, Myrtaceae; Cordeiro et al. 2017), 4-oxoisophorone and 3,5-dimethoxytoluene in Prunus species (apricot, P. armeniaca; European plum, P. domestica; peach, P. persica; all Rosaceae; El-Sayed et al. 2018) and linalool and linalool oxides in guarana (Paullinia cupana, Sapindaceae; Krug et al. 2018). All these floral scent compounds are also known from non-crop plants (Knudsen et al. 2006), and some thereof, such as 2-phenylethanol and linalool, also known to being involved in communication between such plants and their pollinators (Dobson 2006).

The pear is with c. 22 million tons (data of 2013) the second most important pomaces fruit produced in the world (WAPA 2019). Most pear cultivars (Pyrus communis L.) rely on insect pollination, as flowers are self-incompatible (Schanderl 1937; Schumacher 1989; Free 1993; Delaplane et al. 2000; Jackson 2003). The Western honey bee (Apis mellifera L.) occurs in most of the (commercial) orchards and is overall the most important pollinator of pear (Stephen 1958; McGregor 1976; Free 1993; Delaplane et al. 2000; Jackson 2003; Monzón et al. 2004). Only in some orchards is the solitary bee Osmia cornuta used as managed pollinator, and in these cases as effective as the honey bee (Monzón et al. 2004). The impact on pollination of dipteran and lepidopteran species, which also visit pear flowers (Mc Gregor 1976 and references therein), was not yet investigated.

Flowers of the European pear release a strong scent to the human nose; however, the scents specifically released from flowers were not identified so far. One study, however, described volatiles released from young flowering pear plants in a Teflon chamber (Baraldi et al. 1999). Thereby, 23 compounds, mainly aliphatic compounds and monoterpenes, were detected. The monoterpenes, which were the only compounds analysed quantitatively, consisted mainly of linalool $(70 \%)$ and to a lesser extent of $\alpha$-pinene, limonene, and $\beta$-myrcene. All these compounds are common floral volatiles, described from more than $60 \%$ of the plant families (Knudsen et al. 2006). None of these compounds does explain why the flower scent of pear is unpleasant and reminiscent of ammonia.

In the present study, we analysed floral scents of several European pear cultivars and identified compounds being biologically active in antennae of honey bees. Given that compounds involved in pollinator attraction (as is true for compounds eliciting repellent responses) typically elicit physiological responses in antennae of insects, GC (gas chromatography) coupled to EAD (electroantennographic detection) is an elegant way to identify those compounds among the ones detected in chemical analytical analyses that are physiologically and potentially also behaviourally active (Schiestl and Marion-Poll 2002). So far, this technique identified several compounds biologically active in bees (i.e., Thiery et al. 1990; Henning et al. 1992; Henning and Teuber 1992; Wadhams et al. 1994; Dötterl 2008; Dötterl and Vereecken 2010; Klatt et al. 2013, Jürgens et al. 2014; Mas et al. 2018) and, in combination with behavioural assays, presented the chemical basis of plant-pollinator interactions (Burger et al. 2010; Milet-Pinheiro et al. 2013, 2015; Schäffler et al. 2015).

The aim of this study was to chemically characterize the floral scent of pear, which is strong and reminiscent of ammonia, and to identify those compounds thereof, which are physiologically active in honey bees, its main pollinator. Specifically, we identified (i) compounds emitted by the flowers of ten pear cultivars using (high resolution) gas chromatography coupled to mass spectrometry (GC/MS), nuclear magnetic resonance (NMR), and chemical synthesis and (ii) analysed the antennal responses of honey bees (A. mellifera) to the emitted volatiles using GC/EAD.

\section{Materials and methods}

\section{Study sites}

Investigations were conducted in the organic nursery `Silva Nortica' in Bad Großpertholz (BGPH, 800 m a.s.l.) Austria, and on a private property in Marktschellenberg (MSB, $650 \mathrm{~m}$ a.s.1.), Germany. Annual rainfall and average temperature are with $1200 \mathrm{~mm}$ and $9{ }^{\circ} \mathrm{C}$, respectively, in MSB higher compared to $900 \mathrm{~mm}$ and $6.5^{\circ} \mathrm{C}$, respectively, in BGPH (Climate Data 2019). Both study sites are surrounded by meadows and wooded hills with mainly larch, spruce, and beech trees.

\section{European pear cultivars}

Worldwide, there are about 1500 pear cultivars, of which only a few varieties are commercially important (e.g., 'Conference', 'Alexander Lucas'; Agrar Markt Austria 2018; Oekolandbau 2015). We used nine known (all available in $\mathrm{BGPH})$ and one unknown (CU; available in MSB) cultivar(s) of Pyrus communis for volatile collections. The known cultivars were: 'Alexander Lucas' (AL), 'Clapps Liebling' (CL), 'Conférence' (C), 'Köstliche von Charneux' (KC), 'Kongressbirne' (KB), 'Gräfin von Paris' (GP), 'Thirriot' (T), 'Vereinsdechantsbirne' (VDB), and 'Winterdechantsbirne' (WDB). All these cultivars are old varieties, which were select due to their importance in 
Europe and their availability in the nursery. One individual was available for each cultivar except for $\mathrm{AL}$ and $\mathrm{CL}$, for which two individuals each were used (AL 1, AL 2, CL 1, and CL 2). Sampled trees were between 3 and 20 years old. This sampling regime does not allow to specifically test for differences in scent among cultivars, however, gives a good overview of volatiles released from common pear. Thus, when we subsequently use the term "cultivar", we talk about the scent of a single or two trees of a specific cultivar and not about a cultivar as a whole.

\section{Volatile sampling}

Floral scent was collected for compound identification and electrophysiological analysis from flowers in full bloom (we did not determine the exact age of the flowers) on trees of the known varieties (in situ) using dynamic headspace. Flower clusters with 5-14 flowers were enclosed in polyethylene oven bags (ca. $30 \times 15 \mathrm{~cm}$; Toppits ${ }^{\circledR}$, Melitta, Germany). Subsequently, volatiles were adsorbed in small tubes (Varian Inc. ChromatoProbe quartz microvials; $1.5 \mathrm{~cm}$ long, external diameter $0.25 \mathrm{~cm}$, internal diameter $0.2 \mathrm{~cm}$ ) filled with $1.5 \mathrm{mg}$ each of Tenax-TA (mesh 60-80) and Carbotrap B (mesh 20-40; both Supelco, Bellefonte, PA, USA) by pulling the air inside the bag through the tubes for 15-20 min using a membrane pump (G12/01 EB, Rietschle Thomas Inc., Puchheim, Germany; Flow rate:

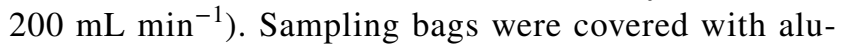
minium foil to avoid direct solar irradiation, which would result in the condensation of high amounts of water inside the bags. All trees were sampled once, except KB which was sampled twice (different flowers, data averaged). Vegetative controls, for discriminating between floral and vegetative scents, were collected from non-flowering shoots ( $20 \mathrm{~cm}$ from tip) of VDB, WDB, and twice of AL 2 using the method as described before. Controls were only taken from some of the cultivars, as we expect that the vegetative scents are similar among cultivars. Indeed, the vegetative samples of the three cultivars were very similar (unpublished data).

Volatile sampling for electroantennographic analyses and high-resolution MS (see below) was conducted similar as described before but with larger adsorbent tubes $(8 \mathrm{~cm}$ long, external diameter $0.6 \mathrm{~cm}$, internal diameter $0.4 \mathrm{~cm}$ ), filled with $10 \mathrm{mg}$ Tenax-TA and $10 \mathrm{mg}$ Carbotrap B. Samples were collected on 7-10 flowers of AL 2, T, VDB, WDB (BGPH) and CU (MSB) for $4.5 \mathrm{~h}$ each. These five cultivars used for electrophysiology nicely represented the scents overall detected in the present study (see also results, Table 1). Trapped volatiles were eluted with $80 \mu$ acetone (SupraSolv, Merck KgaA, Germany; Dötterl et al. 2005). Overall, samples were collected between 10 a.m. and 6 p.m.

\section{Chemical analysis}

Headspace samples collected with the smaller tubes were analysed with an automatic thermal desorption (TD) system (model TD-20, Shimadzu, Japan) coupled with a GC/ MS (model QP2010 Ultra El, Shimadzu, Japan), which was equipped with a ZB-5 fused silica column (5\% phenyl polysiloxane; $60 \mathrm{~m}$ long, inner diameter $0.25 \mathrm{~mm}$, film thickness, $0.25 \mu \mathrm{m}$, Phenomenex, Aschaffenburg, Germany). Samples were run with a split ratio of $1: 1$ and helium was used as carrier gas (flow: $1.5 \mathrm{~mL} \mathrm{~min}^{-1}$ ). The temperature of the GC oven started at $40{ }^{\circ} \mathrm{C}$, increased with $6{ }^{\circ} \mathrm{C}$ per min to $250{ }^{\circ} \mathrm{C}$, and was held constant for $1 \mathrm{~min}$. The MS interface worked at $250{ }^{\circ} \mathrm{C}$. Mass spectra were obtained at $70 \mathrm{eV}$ (El mode) from mass-to-charge ratio $(\mathrm{m} / \mathrm{z})$ 34-350. GC/MS data were processed using the GCMSolution package, Version 4.41 (Shimadzu Corporation; Heiduk et al. 2015; Oliveira et al. 2017). Components were tentatively identified using both the mass spectral libraries Adams (2007), FFNSC2, W9N11, and ESSENTIAL OILS (available in MassFinder 3) and the Kovats retention indices (KRI, based on $n$-alkane series) of compounds. We only considered compounds which had a calculated Kovats index \pm 10 compared to various data bases (Nist11, Adams 2007; El-Sayed 2019). Some of the components were confirmed by comparison of mass spectra and retention times with standard components available in the reference collections of the Plant Ecology Lab of the University of Salzburg and the Institute of Organic Chemistry of the Technische Universität Braunschweig (Table 1).

Compounds found in leaf samples were compared to those emitted from flowers. Volatiles were considered as floral compounds when they were absent in leaf samples or at least in seven times higher amounts in floral than in leaf samples. For quantitative analysis of volatiles $100 \mathrm{ng}$ each of ca. 150 components, among them monoterpenes (e.g., $\alpha$-pinene, linalool, linalool oxide furanoid, and lilac alcohol), aliphatic [e.g., (Z)-3-hexen-1-ol, (Z)-3-hexen-1-yl butyrate, hexanal, ethyl isovalerate, 2-tridecanone], and aromatic (e.g., benzaldehyde, benzyl acetate, benzyl benzoate, and anisaldehyde) compounds were injected into the GC/ MS system. The mean of the peak areas (total ion current) of these compounds was used to estimate the total amount of scent available in the scent samples (Marotz-Clausen et al. 2018). A dilution series of a selected subset of these compounds revealed a linear response factor at the dosages relevant for the present study.

Solvent scent samples were analysed using a GC/MS (QP2010 Ultra, Shimadzu) provided with an AOC-20i autoinjector (Shimadzu, Tokyo, Japan). The GC was equipped with a ZB 5 fused silica column (5\% phenyl polysiloxane; $30 \mathrm{~m}$ long, inner diameter $0.32 \mathrm{~mm}$, film thickness $0.25 \mu \mathrm{m}$, Phenomenex) and helium was used as carrier gas (flow: $3 \mathrm{~mL} \mathrm{~min}^{-1}$ ). Samples $(1 \mu \mathrm{l}$; split ratio: 1:1) were 


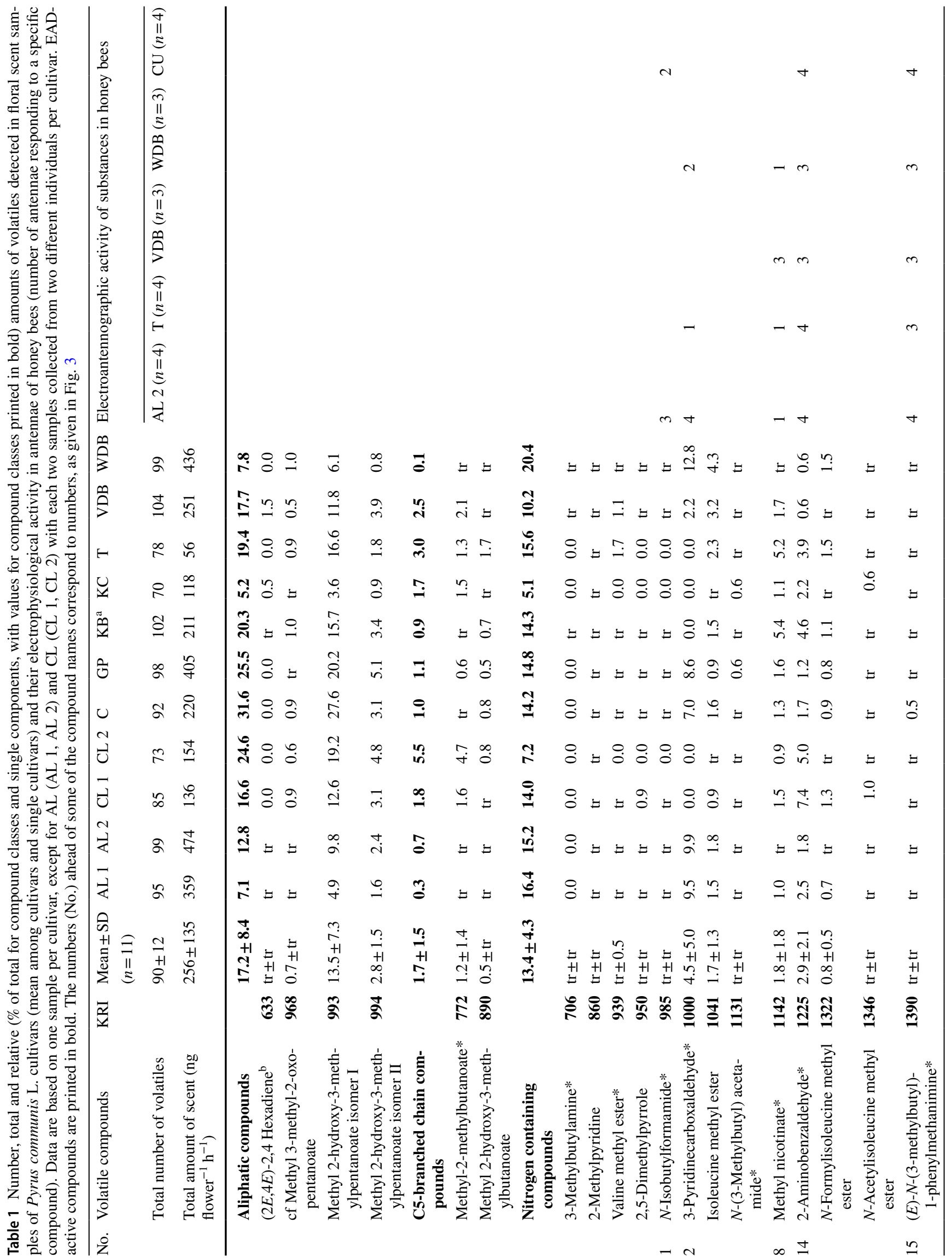




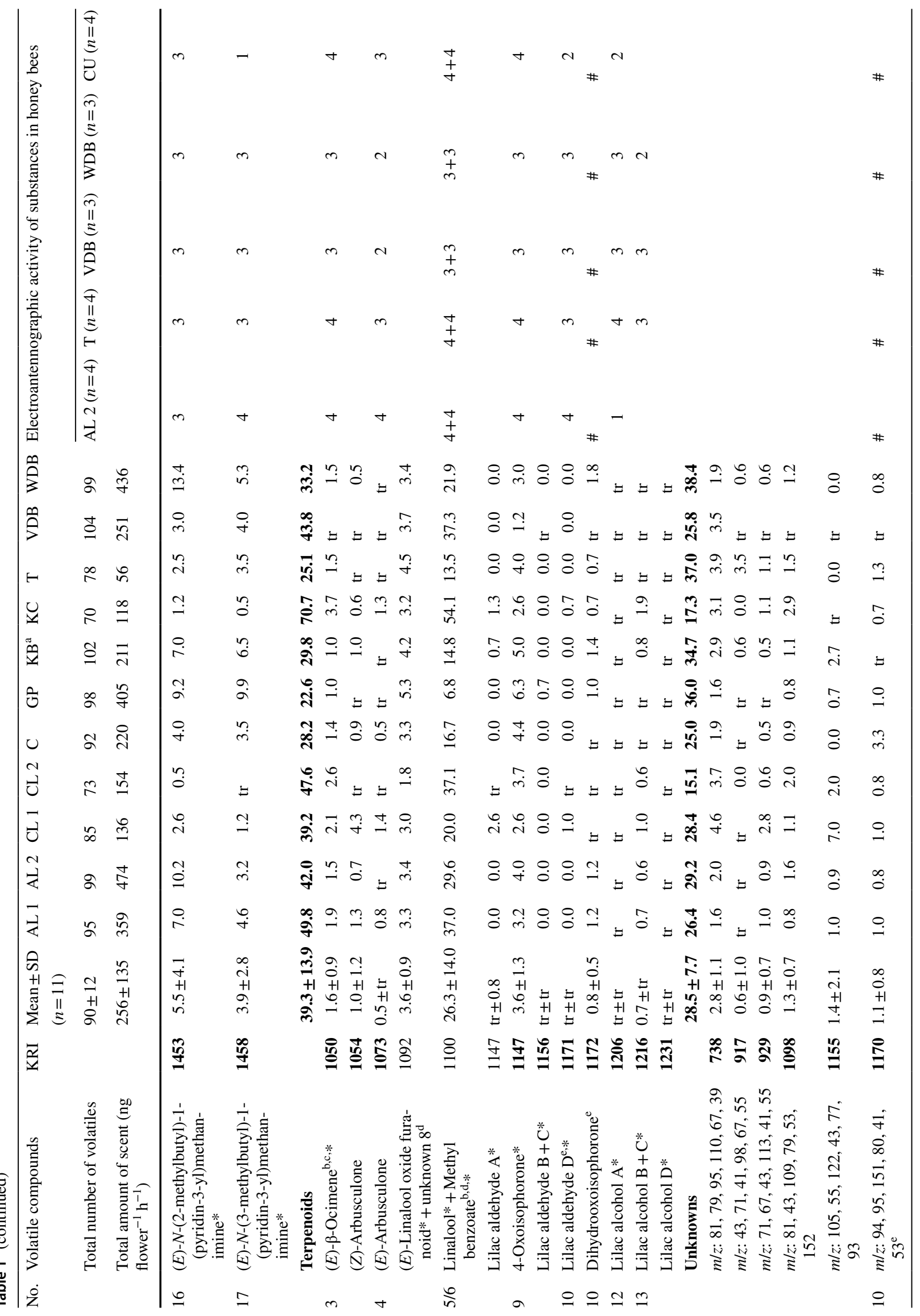




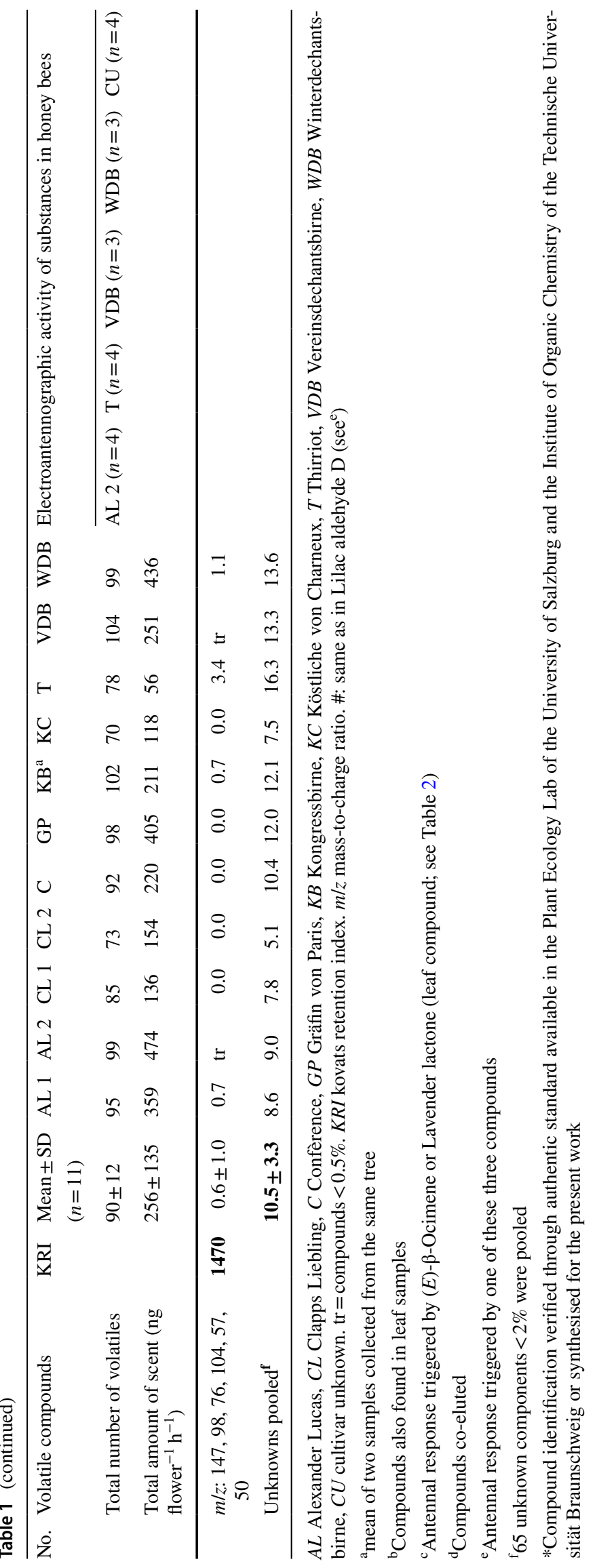


injected at $200{ }^{\circ} \mathrm{C}$. The effluent of the column was split (AFT splitter package, Shimadzu) into two capillaries. One thereof transferred two-thirds of the effluent to a connected EAD system (not used in this study), the other transferred one-third of the effluent to the MS. Temperature of the GC oven started at $40{ }^{\circ} \mathrm{C}$ (held for $1 \mathrm{~min}$ ), then increased by $10{ }^{\circ} \mathrm{C}$ per min to $220^{\circ} \mathrm{C}$ and held for $2 \mathrm{~min}$. The MS interface worked at $220{ }^{\circ} \mathrm{C}$ and the ion source at $200{ }^{\circ} \mathrm{C}$. Mass spectra were taken at $70 \mathrm{eV}$ (El mode) from $\mathrm{m} / z$ 30-350 and data were processed as described above (see also Heiduk et al. 2015; Zito et al. 2015).

\section{Identification of (E)-N-(2-methylbutyl)- and (E)-N-(3- methylbutyl)-1-(pyridin-3-yl)methanimine}

Two novel compounds not found in nature before, $(E)-N-(2-$ methylbutyl)- and (E)- $N$-(3-methylbutyl)-1-(pyridin-3-yl) methanimine (Fig. 1), were identified by analysis of their mass spectra, high-resolution mass spectrometry (HRMS) data, and synthesis. HRMS data were obtained with a gas chromatograph (GC 6890, Agilent Technologies) equipped with a Phenomenex ZB5-MS column (30 m long, inner diameter $0.25 \mathrm{~mm}$ film thickness $0.25 \mu \mathrm{m}$ ) coupled to timeof-flight mass spectrometer (JMS-T100GC, GCAccuTOF, JEOL, Japan) in EI mode (70 eV). JEOL MassCenter ${ }^{\mathrm{TM}}$ workstation software was used. The acquisition range was from $\mathrm{m} / \mathrm{z} 41-700$ with a spectrum-recording interval of $0.4 \mathrm{~s}$. The system was tuned with Perfluoro kerosene to achieve a resolution of 5000 (full width at half maximum) at $m / z 292.9824$.

(E)-N-(2-methylbutyl)- and (E)- $N$-(3-methylbutyl)-1(pyridin-3-yl)methanimine were synthesised by imine formation from 3-pyridinecarboxaldehyde and 2-methylbutylamine or 3-methylbutylamine, respectively, according to our procedure published earlier (Harig et al. 2017).

(E)-N-(2-methylbutyl)-1-(pyridin-3-yl)methanimine: ${ }^{1} \mathrm{H}$ NMR $\left(300 \mathrm{MHz}, \mathrm{CDCl}_{3}\right) \delta 8.86(\mathrm{dd}, J=2.2,0.8 \mathrm{~Hz}, 1 \mathrm{H})$, $8.64(\mathrm{dd}, J=4.8,1.7 \mathrm{~Hz}, 1 \mathrm{H}), 8.31-8.25(\mathrm{~m}, 1 \mathrm{H}), 8.11(\mathrm{~d} t$, $J=7.9,2.0 \mathrm{~Hz}, 1 \mathrm{H}), 7.34$ (dddd, $J=7.9,4.8,0.5 \mathrm{~Hz}, 1 \mathrm{H}$ ), 3.61 (ddd, $J=11.4,5.8,1.5 \mathrm{~Hz}, 1 \mathrm{H}), 3.42$ (ddd, $J=11.5$, $7.1,1.3 \mathrm{~Hz}, 1 \mathrm{H}), 1.92-1.62(\mathrm{~m}, 1 \mathrm{H}), 1.66-1.34(\mathrm{~m}, 1 \mathrm{H})$, $1.33-1.14(m, 1 \mathrm{H}), 1.00-0.90(m, 3 \mathrm{H}) .{ }^{13} \mathrm{C} \mathrm{NMR}(76 \mathrm{MHz}$, $\left.\mathrm{CDCl}_{3}\right) \delta 157.86(\mathrm{~N}=\mathrm{CH}), 151.29(\mathrm{Ar}-\mathrm{CH}), 150.19$ $(\mathrm{Ar}-\mathrm{CH}), 134.36(\mathrm{Ar}-\mathrm{CH}), 131.86(\mathrm{Cq}), 123.60(\mathrm{Ar}-\mathrm{CH})$, $68.13\left(\mathrm{CH}_{2}\right), 35.97(\mathrm{CH}), 27.50\left(\mathrm{CH}_{2}\right), 17.72\left(\mathrm{CH}_{3}\right), 11.42$ $\left(\mathrm{CH}_{3}\right) \cdot \mathrm{RI}=1438$. Smell: fruity, pear note.

(E)-N-(3-methylbutyl)-1-(pyridine-3-yl)methanimine: ${ }^{1} \mathrm{H}$ NMR $\left(300 \mathrm{MHz}, \mathrm{CDCl}_{3}\right) \delta 8.85(\mathrm{dd}, J=2.2,0.8 \mathrm{~Hz}$, $1 \mathrm{H}), 8.64(\mathrm{dd}, J=4.8,1.7 \mathrm{~Hz}, 1 \mathrm{H}), 8.36-8.28(m, 1 \mathrm{H})$, $8.10(\mathrm{~d} t, J=8.0,2.1 \mathrm{~Hz}, 1 \mathrm{H}), 7.34$ (dddd, $J=7.9,4.8,0.9$, $0.5 \mathrm{~Hz}, 1 \mathrm{H}), 3.72-3.60(\mathrm{~m}, 2 \mathrm{H}), 1.80-1.52(\mathrm{~m}, 3 \mathrm{H}), 0.95$ $(\mathrm{d}, J=6.4 \mathrm{~Hz}, 6 \mathrm{H}) \cdot{ }^{13} \mathrm{C} \mathrm{NMR}\left(76 \mathrm{MHz}, \mathrm{CDCl}_{3}\right) \delta 157.70$ $(\mathrm{N}=\mathrm{CH}), 151.32(\mathrm{Ar}-\mathrm{CH}), 150.16(\mathrm{Ar}-\mathrm{CH}), 134.30$
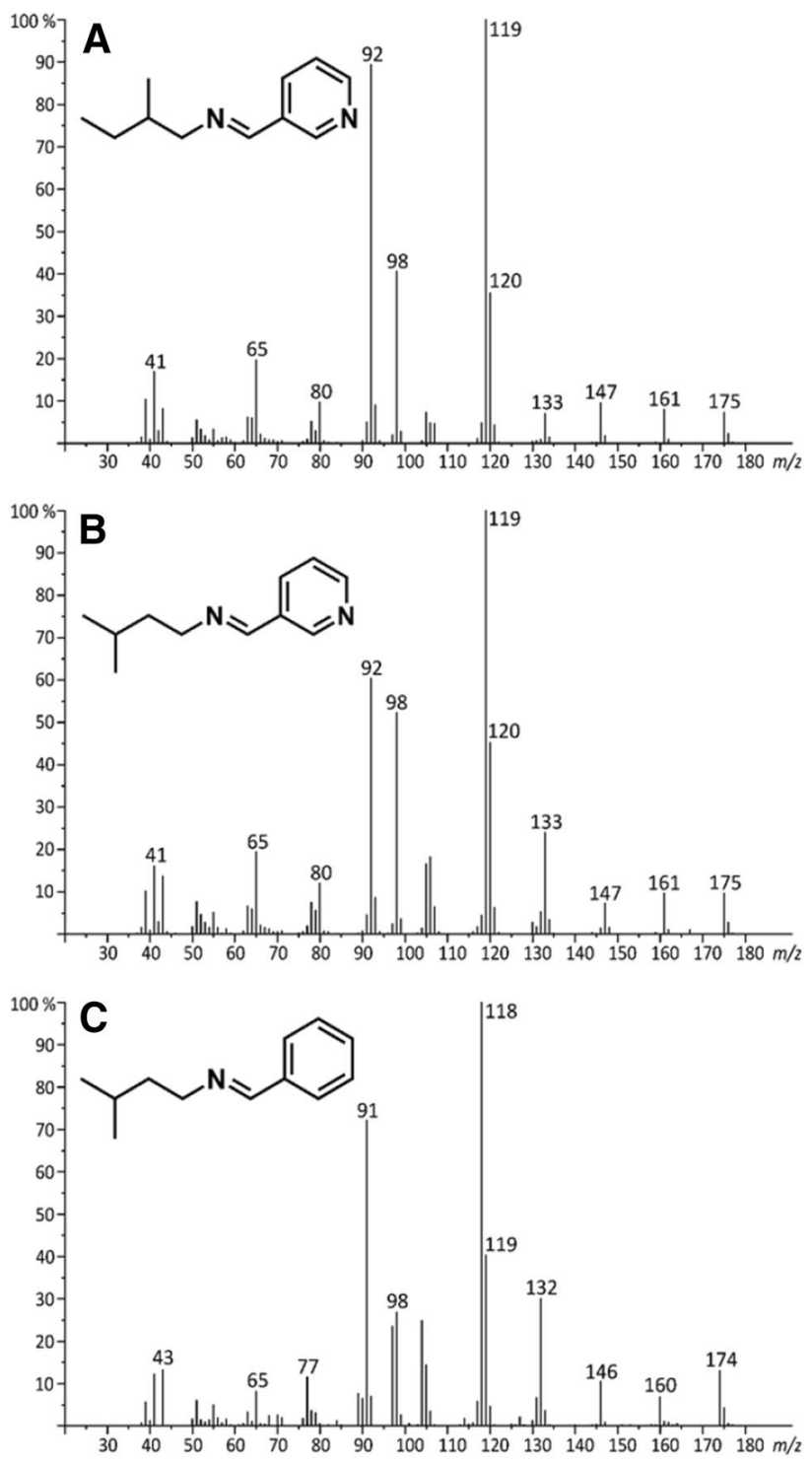

Fig. 1 Mass spectra and structure of the two novel compounds $(E)$ $\mathrm{N}$-(2-methylbutyl)-1-(pyridin-3-yl)methanimine (A) and (E)-N-(3methylbutyl)-1-(pyridin-3-yl)methanimine (B) as well as a structurally related compound (E)-N-(3-methylbutyl)-1-phenylmethanimine (C) identified in pear floral volatile samples

$(\mathrm{Ar}-\mathrm{CH}), 131.87(\mathrm{Cq}), 123.60(\mathrm{Ar}-\mathrm{CH}), 60.12\left(\mathrm{CH}_{2}\right)$, $39.83\left(\mathrm{CH}_{2}\right), 25.99(\mathrm{CH}), 22.56\left(2 \times \mathrm{CH}_{3}\right) . \mathrm{RI}=1442$. Smell: fruity, pear note.

\section{Electrophysiological analysis}

Electrophysiologically active compounds in antennae of worker honey bees (A. mellifera) were detected using GC/ EAD. Therefore, 15 and 13 bees were collected in the Botanical Garden of the University of Salzburg while visiting flowers from mainly Geranium pratense and some other herbaceous flowers in 2016 and 2017, respectively, and stored in the dark 
at $4{ }^{\circ} \mathrm{C}$. Antennae were cut off at the base and the tip and placed between two capillaries, filled with ringer solution (8.0 $\mathrm{g} \mathrm{L}^{-1} \mathrm{NaCl}, 0.4 \mathrm{~g} \mathrm{~L}^{-1} \mathrm{KCl}, 0.4 \mathrm{~g} \mathrm{~L}^{-1} \mathrm{CaCl}_{2}$ ). The base of an antenna was taken up by the reference capillary, while the tip was connected to the recording capillary. The capillaries were contacted to silver wires and placed in front of the GC outlet (Heiduk et al. 2015).

For measurements, a GC (Agilent 7890 A Santa Clara, CA, USA) equipped with a flame ionization detector (FID) and an electroantennographic detection system (GC/EAD) was used. The EAD system contained a transfer line, heated at $220{ }^{\circ} \mathrm{C}$, and a 2-Channel USB acquisition controller (Syntech, Kirchzarten, Germany). The GC was equipped with a ZB-5 fused silica column (5\% phenyl polysiloxane; $30 \mathrm{~m}$ long, inner diameter $0.32 \mathrm{~mm}$, film thickness $0.25 \mu \mathrm{m}$, Phenomenex) using hydrogen as carrier gas (flow: $3 \mathrm{~mL} \mathrm{~min}^{-1}$ ). At the end, a $\mu$ Flow splitter (Gerstel, Mülheim, Germany) separated the column into two capillaries of which one led to the FID ( $2 \mathrm{~m} \times 0.15 \mu \mathrm{m}$ inner diameter) and the other one to the EAD $\left(1 \mathrm{~m} \times 0.2 \mu \mathrm{m}\right.$ inner diameter) setup. Nitrogen $\left(\mathrm{N}_{2}\right)$ was used as make-up gas at a flow rate of $25 \mathrm{~mL} \mathrm{~min}^{-1}$ (Heiduk et al. 2015; Zito et al. 2015). Scent samples were injected ( $\left.1 \mu \mathrm{l} ; 250{ }^{\circ} \mathrm{C}\right)$ in splitless mode. The GC oven was heated to $40{ }^{\circ} \mathrm{C}$ and held constant for $1 \mathrm{~min}$. After $0.5 \mathrm{~min}$, the split vent opened, the temperature increased by $10^{\circ} \mathrm{C}$ per min to $220^{\circ} \mathrm{C}$ and was held constant for $2 \mathrm{~min}$.

In 2016, responses of antennae of 10 out of the 15 bee individuals and in 2017, four out of the 13 bee individuals were used for analyses, as responses of antennae of other bees were too noisy to be analysed. Three individuals each were tested on scent samples of the cultivars VDB and WDB and four individuals each on AL 2, T and CU, with some bee individuals used for more than one cultivar. Volatiles were described as EAD-active if they showed responses in at least five different bee individuals, independent from the cultivar.

\section{Statistical analysis}

Pairwise qualitative (presence and absence of compounds; Sørensen index) and semiquantitative (relative amount of scent components; Bray-Curtis index) similarities in scent pattern among samples were calculated with Primer (version 6.1.15). These similarity matrices were used to visualise similarities and dissimilarities in scent among samples using non-metric multidimensional scaling (NMDS; Clarke and Gorley 2005).

\section{Results}

\section{Flower scent}

The absolute amount of floral volatiles, collected on eleven $P$. communis trees (nine cultivars), was highly variable
(56-474 ng flower ${ }^{-1} \mathrm{~h}^{-1}$; Min-Max), with an average of $256 \pm 135 \mathrm{ng}$ flower $^{-1} \mathrm{~h}^{-1}$ (mean $\pm \mathrm{SD}$; Table 1). Overall, we detected 108 compounds, with 70-104 volatiles per tree/ cultivar: 13 terpenoids (together in the mean among cultivars $39 \pm 14 \%$ of the total amounts of scent), 15 nitrogen containing compounds $(13 \pm 4 \%)$, four aliphatic compounds $(17 \pm 8 \%)$, two branched $\mathrm{C}_{5}$ aliphatic compounds $(2 \pm 2 \%)$, one aromatic compound (methyl benzoate; co-eluted with linalool), and 73 unknown compounds $(29 \pm 8 \%)$. Of these 108 compounds, (E2,E4)-2,4-hexadiene, $(E)$ - $\beta$-ocimene and linalool were also present in leaf samples, but with amounts at least seven times lower than in floral samples. Overall, 52 compounds were found in all cultivars, 78 in at least eight cultivars, and 86 in at least seven cultivars. Only 10 compounds were found in five or less cultivars, showing that there was a large overlap in scent among the different cultivars. Indeed, six (AL (1 and 2), C, GP, KB, VDB, and WDB) of the nine cultivars emitted a quite similar spectrum of volatiles, with at least 92 compounds per cultivar (Fig. 2A; Table 1), whereas samples collected from trees of $\mathrm{KC}, \mathrm{CL}$ ( 1 and 2 ) and $\mathrm{T}$ contained less components (70-85).

More variation in scent among cultivars occurred when focusing on semiquantitative scent patterns (Fig. 2B). Most obvious was the variation in the relative amounts of linalool + methyl benzoate, which dominated the scents of five cultivars (20-54\%; KC, VDB, CL, AL, WDB), and methyl 2-hydroxy-3-methylpentanoate, which was the most abundant component in four cultivars (16-28\%; C, GP, KB, T; Fig. 2B; Table 1). Other compounds were also abundant ( $>10 \%$ in at least one cultivar) with obvious variation among cultivars. For example, $(E)-N$-(2-methylbutyl)-1(pyridine-3-yl)methanimine (see below for identification of this compound) was most abundant in WDB (13\%), but contributed only $0.5 \%$ in CL 2 (Table 1). 3-Pyridinecarboxaldehyde was detected in five cultivars (WDB, AL, GP, C, and VDB) with amounts up to $13 \%$, whereas it was absent in the other cultivars. (E)-N-(3-methylbutyl)-1-(pyridine-3-yl) methanimine was also variable among cultivars/individuals, with only trace amounts in CL 2 and 10\% in GP. 2-Aminobenzaldehyde did not reach values higher than $8 \%$ in any cultivar; however, the cultivars with the smallest loading on dimension two of the ordination (Fig. 2B) had higher relative amounts (4-7\%) of this component than all other cultivars (1-3\%; Table 1). Among the unknowns, nine of the volatiles contributed at least a share of $2 \%$ and in the maximum $13 \%$ to the total amount of volatiles released by a cultivar/ individual, whereas the other unknowns were less abundant.

\section{Identification of novel components}

The compounds $(E)-N$-(2-methylbutyl)- and $(E)-N-(3-$ methylbutyl)-1-(pyridin-3-yl)methanimine (Fig. 1A, B) were newly identified in the present work. They showed similar 


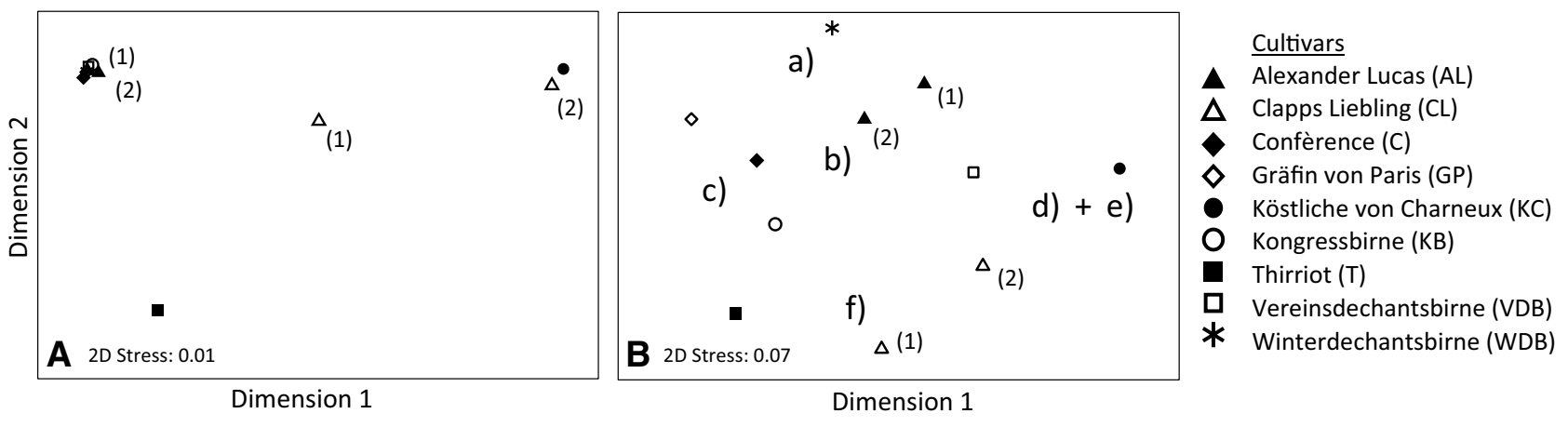<smiles>CCC(C)C/N=C/c1cccnc1</smiles>

Fig. 2 Non-metric multidimensional scaling (NMDS) of qualitative (A) and semiquantitative (B) properties of scent samples collected from different cultivars of pear. A NMDS is based on pairwise qualitative Sørensen indices; B NMDS is based on quantitative BrayCurtis indices calculated on the relative amount of the scent components. Compounds with a relative contribution of at least $10 \%$ in any of the cultivars are indicated a) 3-pyridincarboxaldehyde, b) (E)- $N$ (2-methylbutyl)-1-(pyridin-3-yl)methanimine, c) methyl 2-hydroxy-

mass spectra, and HRMS data revealed the molecular composition to be $\mathrm{C}_{11} \mathrm{H}_{16} \mathrm{~N}_{2}$ (found 176.13,262 and 176.13,370, calc. 176.13135). The major ions $m / z, 92,98$, and 119 had compositions of $\mathrm{C}_{6} \mathrm{H}_{6} \mathrm{~N}, \mathrm{C}_{6} \mathrm{H}_{12} \mathrm{~N}$, and $\mathrm{C}_{7} \mathrm{H}_{7} \mathrm{~N}_{2}$, respectively. The mass spectra resembled those of (E)-N-(3-methylbutyl)1-phenylmethanimine (Fig. 1C; Table 1), but with a shift of the intense ions $\mathrm{m} / \mathrm{z} 91$ and 118 in the latter to $\mathrm{m} / \mathrm{z} 92$ and 119 in the newly identified pear compounds (Harig et al. 2017). This shift suggested the target compounds to be imines, derived from 3-pyridinecarboxaldehyde present in the pear volatiles. Our structural proposal was verified by synthesis of the imines derived from 2- and 3-methylbutylamine and 3-pyridinecarboxaldehyde. Comparison of the synthetic material with the unknown compounds revealed them to be (E)-N-(2-methylbutyl)- and (E)-N-(3methylbutyl)-1-(pyridin-3-yl)methanimine, respectively. These compounds have a fruity odour and do not explain the ammonia-like odour of the flowers.

\section{Electrophysiological analysis}

Antennae of A. mellifera responded 19 times, to overall 22 partly coeluting compounds (Fig. 3). Of these components, 17 were categorised as floral volatiles (Table 1), whereas five were mainly released from leaves (Table 2). Linalool, methyl benzoate, 4-oxoisophorone, 2-aminobenzaldehyde and $N$-(3-methylbutyl)-1-phenylmethanimine,
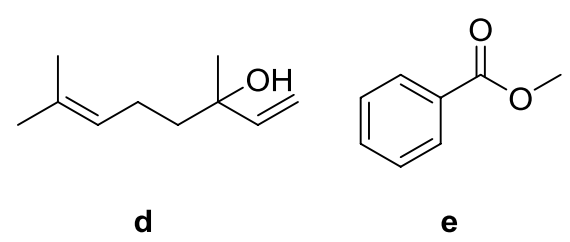<smiles>Nc1ccccc1C=O</smiles>

3-methyl-petanoate, d) linalool, e) methyl benzoate; f) 2-aminobenzaldehyde), with the position in the ordination pointing to the taxon/ taxa having the compounds in highest amounts; 2-aminobenzaldehyde was plotted, as it occurred in Clapps Liebling in a relative amount more than twofold higher than in any other cultivar. (1) and (2) indicate the two different individual samples of both Alexander Lucas (AL) and Clapps Liebling (CL)

(E)- $\beta$-ocimene + lavender lactone (leaf volatile), and methyl salicylate (leaf volatile) were EAD-active in all 14 bee individuals. Six other compounds were active in more than $70 \%$ of the bees tested, including the two novel compounds. Among the EAD-active compounds were main (e.g., linalool + methyl benzoate) as well as minor compounds (e.g., lilac alcohols, (E)- $N$-(3-methylbutyl)-1-phenylmethanimine). Together, the EAD-active compounds contributed in the mean (among cultivars) 53\% to the total scent emitted.

\section{Discussion}

We found that flowers of Pyrus communis cultivars emit a wide range of volatile compounds. Many of them have not been identified in the previous studies on plant scents in pear. The antennae of honey bees were sensitive to 17 of the 108 floral compounds, which suggests that only a fraction of the olfactory phenotype is involved in signaling between pear flowers and the honey bee. Two of the EAD-active volatiles were not known from nature before and, therefore, identified as new natural compounds.

Despite being from different cultivars, the different samples were qualitatively quite similar, with many of the 108 detected compounds occurring in all samples/cultivars (Table 1). More variable, however, were the total amounts and the relative scent patterns among samples (Table 1, 


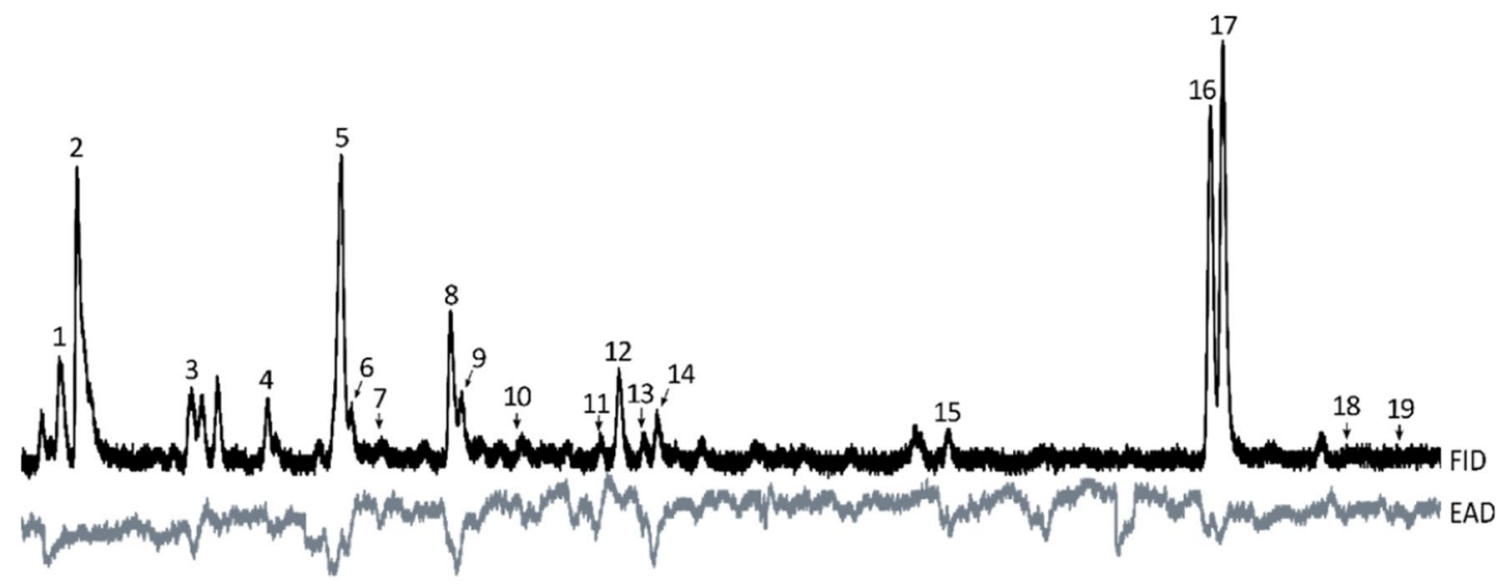

Fig. 3 Representative example of electroantennographic responses of an Apis mellifera antenna (EAD: Electroantennographic detection) to a floral scent sample of Pyrus communis (FID: Flame ionization detection; cultivar Thirriot). Responses are numbered and correspond to numbers (No.) in Table 1

Table 2 EAD-activity of vegetative pear volatiles in antennae of Apis mellifera. The number of runs $(n)$ performed with samples of the different cultivars is also given. The numbers (No.) ahead of the compound names correspond to numbers, as given in Fig. 3

\begin{tabular}{|c|c|c|c|c|c|c|c|}
\hline \multirow[b]{2}{*}{ No. } & \multirow[b]{2}{*}{ Volatile compound } & \multirow[b]{2}{*}{ KRI } & \multicolumn{5}{|c|}{ Number of responding bees } \\
\hline & & & $\operatorname{AL~} 2(n=4)$ & $\mathrm{T}(n=4)$ & $\operatorname{VDB}(n=3)$ & $\mathrm{WDB}(n=3)$ & $\mathrm{CU}(n=4)$ \\
\hline 3 & Lavender lactone $^{\mathrm{a}}$ & 1044 & 4 & 4 & 3 & 3 & 4 \\
\hline 7 & (E)-4,8-Dimethyl-1,3,7-nonatriene* & 1116 & 4 & 4 & 3 & 3 & 4 \\
\hline 11 & Methyl salicylate* & 1202 & 4 & 4 & 3 & 3 & 4 \\
\hline 18 & $m / z: 93,41,57,55,69,107$ & 1510 & 1 & & 2 & & 4 \\
\hline 19 & $m / z: 139,118,91,44,161,80$ & 1533 & 2 & 4 & 3 & 3 & 3 \\
\hline
\end{tabular}

$A L$ Alexander Lucas, $T$ Thirriot, $V D B$ Vereinsdechantsbirne, $W D B$ Winterdechantsbirne. KRI Kovats retention index. $m / z$ mass-to charge ratio ${ }^{a}$ response might also have been towards (E)- $\beta$-ocimene

*Compound identification verified through authentic standards available in the Plant Ecology Lab of the University of Salzburg and the Institute of Organic Chemistry of the Technische Universität Braunschweig, or synthesised for the present work

Fig. 2). Future work should test, by analysing the scent of various individuals per cultivar, whether the observed variability among samples is due to a true cultivar effect or other reasons, such as the age of flowers. Pear (floral) volatiles were once investigated before (Baraldi et al. 1999). There is only a very limited overlap in the number, amount, and identity of volatiles described previously and in the present study. Compared to Baraldi et al. (1999), we found a 4-fold higher number of compounds and a 100-fold higher amount of scent trapped per flower. Except for linalool, no compound was common to both studies. Thus, except for this monoterpenoid, all other compounds are described here for the first time as floral volatiles of pear. One other monoterpenoid detected in the present study; however, $(E)$ - $\beta$-ocimene was described as a leaf volatile in pear by Miller et al. (1989). We also detected this compound in our leaf samples; however, we classified it as floral volatile, as it occurred in much higher quantities (17-fold) in floral than in leaf samples. Differences between the two pear flower scent studies might be due to a cultivar effect. This, however, is unlikely in this case, because we only found quite small differences in scent among the various cultivars/trees studied. Instead, we believe that the enormous differences in the scent profiles detected are due to a different method of collecting the scents. While in the present study, volatiles were collected from single flower clusters that were enclosed in small oven bags on the tree, Baraldi et al. (1999) sampled the whole tree (full in bloom) in a $300 \mathrm{~L}$ Teflon chamber. From this chamber, they collected $3-6 \mathrm{~L}$ of the air (1-2\% of the air available in the chamber) enriched with the volatiles released from the tree, and thus, a similar amount of the air, as we did (3-4 L). Given that we collected air enriched with the volatiles from a much smaller volume (after bagging c. $1 \mathrm{~L}$ ), we were much more effective in quantitatively trapping the floral volatiles. This seems to be the main reason for the strongly different results of the two studies. As both studies used similar adsorbents (Carbotrap $\mathrm{B}$ and Tenax-TA in our study versus Carbotrap C and Carbotrap in Baraldi et al. (1999)) and thermally desorbed the 
samples, other methodological parameters had likely only minor effects on the differences.

When compared with the review of Knudsen et al. (2006) on floral scent components, it is obvious that some of the compounds released by pear flowers are among the most widespread floral scents [e.g., linalool, $(E)$ - $\beta$-ocimene], whereas many others, among them various nitrogen containing compounds [e.g., valine methyl ester, isoleucine methyl ester, (E)- $N$-(2-methylbutyl)-1-(pyridin-3-yl)methanimine) are less frequently found in floral scents (see also Joulain 1987 for the occurrence of amino acid esters and imines in Sambucus nigra L. flowers] or are described for the first time in nature (see above). Among the compounds rarely found in floral scents is also methyl 2-hydroxy-3-methylpentanoate, which is abundant in pear (see before). To the best of our knowledge, this compound was not described for a Rosaceae species before (Knudsen et al. 2006; El-Sayed et al. 2018; El-Sayed 2019), but is already known from few species of Eupomatiaceae, Nymphaeaceae and Orchidaceae (Knudsen et al. 2006). The scent of P. communis strongly differs from the scent of other crop plants, though some of the compounds identified in pear do also occur in other crop species. Apple (Malus $\times$ domestica) flowers, for example, which are very similar in morphology as pear flowers (MacDaniels 1940), overlap with pear flowers in linalool and $(E)$ - $\beta$-ocimene, whereas all other compounds found in pear (Table 1) and apple (e.g., benzyl alcohol, and benzaldehyde) are only found in the respective species (Loughrin et al. 1990; Baraldi et al. 1999; Bengtsson et al. 2001). Some overlap also exists between pear and wild cherries (Prunus avium), as flowers of both species emit linalool, methyl benzoate, 4-oxoisophorone, lilac aldehydes, and alcohols (ElSayed et al. 2018; Table 1).

The antennae of honey bees responded to main and minor scent compounds of pear, and several of these electroantennographically active compounds were not known to cause physiological and/or behavioural responses in (honey bee) pollinators before (e.g., 3-pyridinecarboxaldehyde; Dötterl and Vereecken 2010; El-Sayed 2019). Other compounds, however, were already identified as being electrophysiologically or even behaviourally active in honey bees (e.g., linalool, lilac aldehyde, 4-oxoisophorone; Henning et al. 1992; Henning and Teuber 1992; Wadhams et al. 1994; Blight et al. 1997; Jürgens et al. 2014). The activity of linalool might be related to the chemical and structural similarities of the compound with the honey bee pheromone geraniol, used for food source recognition (Williams et al. 1982; Henning et al. 1992). Overall, it is very likely that olfactory cues in general are involved in communication between pear flowers and honey bees. More specific linalool and all the other EAD-active compounds might be involved in attracting honey bees and other pollinators to pear flowers, and thus, represent an important step in the fruit production of this economically important plant species. Methyl 2-hydroxy-3-methylpentanoate, which was quite abundant in pear, but is otherwise rarely found as floral scent in other plants (see also above), was not EAD-active in honey bee antennae, and therefore, is likely not responsible for olfactory attraction of honey bees to pear flowers. Otherwise, we cannot exclude that more compounds than the ones identified as EAD-active are perceived by the honey bee. We got non-consistent antennal responses from single antennae to other compounds (see, e.g., non-numbered responses in Fig. 1). Most of these compounds occurred only in trace amounts in the samples, which might have been too small to consistently elicit antennal responses above the noise level.

In this study, we detected many pear floral volatiles with most of them found in all the cultivars studied. All compounds, except linalool, were identified as pear floral volatiles for the first time. Two compounds, $(E)-N-(2-$ methylbutyl)- and (E)-N-(3-methylbutyl)-1-pyridin-3-yl) methanimine, are described as new natural compounds for the first time not only in pear. It is surprising that novel compounds can still be discovered in economically important plants, showing the big gap in our understanding of crop-pollinator and generally of plant-pollinator communication. The two newly identified compounds have a fruity aroma and do not explain the ammonia-like scent of pear. Instead, it seems that a mixture of various other compounds (e.g., 3-methylbutylamine, 3-pyridincarboxaldehyde, methyl 2-hydroxy-3-methylpentanoate) is responsible for the unpleasant scent of the flowers. The new natural compounds, together with several other compounds, were physiologically active in honey bees, and thus, are potentially behaviourally active. The determination of the relative importance of olfactory versus visual cues and the role of single floral scents in attracting honey bees and other pollinators to pear flowers might be the topic of future studies. It also would be interesting to study other potential functions of the volatiles identified in the present study, among them the novel compounds, such as floral filters to exclude other organisms as floral visitors (Johnson et al. 2006; Raguso 2008) or to fight against antagonistic microorganisms (Junker and Tholl 2013).

Acknowledgements Open access funding provided by Paris Lodron University of Salzburg. We thank Martin Artner for the provision of blooming pear trees on his farm, Irmgard Schäffler for her support in the chemical lab of the University of Salzburg, and two anonymous reviewers for helpful comments on an earlier version of the manuscript.

Author contribution Kathrin Lukas and Stefan Dötterl conceived of the presented idea. Kathrin Lukas carried out the experiments, analysed the data, and took the lead in writing the manuscript. Stefan Dötterl supervised the project and supported the manuscript development. Tim Harig and Stefan Schulz identified and synthesised the novel components and 
contributed to the scent analyses and manuscript writing. Johannes Hadersdorfer provided critical feedback to the manuscript.

\section{Compliance with ethical standards}

Conflict of interest The authors declare that they have no conflict of interest.

Open Access This article is distributed under the terms of the Creative Commons Attribution 4.0 International License (http://creativeco mmons.org/licenses/by/4.0/), which permits unrestricted use, distribution, and reproduction in any medium, provided you give appropriate credit to the original author(s) and the source, provide a link to the Creative Commons license, and indicate if changes were made.

\section{References}

Adams RP (2007) Identification of essential oil components by gas chromatography/mass spectrometry, vol 456. Allured Publishing Corporation, Carol Stream

Agrar Markt Austria (2018) Marktübersicht Birnen. https://www.ama. at. Accessed 28 Aug 2019

Balkenius A, Rosèn W, Kelber A (2006) The relative importance of olfaction and vision in a diurnal and a nocturnal hawkmoth. J Comp Physiol A 192:431-437. https://doi.org/10.1007/s0035 9-005-0081-6

Baraldi R, Rapparini F, Rossi F, Latella A, Ciccioli P (1999) Volatile organic compound emissions from flowers of the most occurring and economically important species of fruit trees. Phys Chem Earth Part B Hydrol Oceans Atmos 24:729-732. https://doi. org/10.1016/S1464-1909(99)00073-8

Bengtsson M, Bäckman AC, Liblikas I, Ramirez MI, Borg-Karlson AK, Ansebo L, Anderson P, Löfqvist J, Witzgall P (2001) Plant odor analysis of apple: antennal response of codling moth females to apple volatiles during phenological development. J Agric Food Chem 49:3736-3741. https://doi.org/10.1021/jf0100548

Blight MM, Le Métayer M, Delègue MHP, Pickett JA, Marion-Poll F, Wadhams LJ (1997) Identification of floral volatiles involved in recognition of oilseed rape flowers, Brassica napus by honeybees, Apis mellifera. J Chem Ecol 23:1715-1727. https://doi. org/10.1023/B:JOEC.0000006446.21160.c1

Bogdany FJ, Taber Iii S (1979) The significance of odor for bees orienting across a canyon. Apidologie 10:55-62. https://doi. org/10.1051/apido:19790107

Burger H, Dötterl S, Ayasse M (2010) Host-plant finding and recognition by visual and olfactory floral cues in an oligolectic bee. Funct Ecol 24:1234-1240. https://doi.org/10.111 $1 / j .1365-2435.2010 .01744 . x$

Clarke KR, Gorley RN (2005) Primer v6: user manual/tutorial. PrimerE Ltd, Plymouth

Climate Data (2019) Klima Bad Großpertholz und Marktschellenberg. https://de.climate-data.org. Accessed 28 Aug 2019

Cordeiro GD, Pinheiro M, Dötterl S, Alves-dos-Santos I (2017) Pollination of Campomanesia phaea (Myrtaceae) by night-active bees: a new nocturnal pollination system mediated by floral scent. Plant Biol 19:132-139. https://doi.org/10.1111/plb.12520

Dag A, Zipori I, Pleser Y (2006) Using bumblebees to improve almond pollination by the honeybee. J Apic Res 45:215-216. https://doi. org/10.1080/00218839.2006.11101350

De Jong R, Pham-Delègue MH (1991) Electroantennogram responses related to olfactory conditioning in the honey bee (Apis mellifera ligustica). J Insect Physiol 37:319-324. https://doi. org/10.1016/0022-1910(91)90066-9
Delaplane KS, Mayer DR, Mayer DF (2000) Crop pollination by bees. CABI, Wallingford

Dobson HEM (2006) Relationship between floral fragrance and type of pollinator. In: Dudareva N, Pichersky E (eds) Biology of floral scent. CRC Press, Boca Raton, pp 147-198. https://doi. org/10.1201/9781420004007

Dobson HEM, Danielson EM, Van Wesep ID (1999) Pollen odor chemicals as modulators of bumble bee foraging on Rosa rugosa Thunb. (Rosaceae). Plant Species Biol 14:153-166. https://doi.org/10.1046/j.1442-1984.1999.00020.x

Dogterom MH, Matteoni JA, Plowright RC (1998) Pollination of greenhouse tomatoes by the North American Bombus vosnesenskii (Hymenoptera: Apidae). J Econ Entomol 91:71-75. https:// doi.org/10.1093/jee/91.1.71

Dötterl S (2008) Antennal responses of an oligolectic bee and its cleptoparasite to plant volatiles. Plant Signal Behav 3:296-297. https://doi.org/10.4161/psb.3.5.5271

Dötterl S, Vereecken NJ (2010) The chemical ecology and evolution of bee-flower interactions: a review and perspectives. Can J Zool 88:668-697. https://doi.org/10.1139/Z10-031

Dötterl S, Füssel U, Jürgens A, Aas G (2005) 1,4-Dimethoxybenzene, a floral scent compound in willows that attracts an oligolectic bee. J Chem Ecol 31:2993-2998. https://doi.org/10.1007/s1088 6-005-9152-y

Dötterl S, Milchreit K, Schäffler I (2011) Behavioural plasticity and sex differences in host finding of a specialized bee species. J Comp Physiol A 197:1119-1126. https://doi.org/10.1007/s0035 9-011-0673-2

El-Sayed AM (2019) The pherobase: database of pheromones and semiochemicals. http://www.pherobase.com. Accessed 182017

El-Sayed AM, Sporle A, Colhoun K, Furlong J, White R, Suckling DM (2018) Scents in orchards: floral volatiles of four stone fruit crops and their attractiveness to pollinators. Chemoecolrogy 28:39-49. https://doi.org/10.1007/s00049-018-0254-8

Free JB (1993) Insect pollination of crops. Academic Press Limited, London

Harig T, Schlawis C, Ziesche L, Pohlner M, Engelen B, Schulz S (2017) Nitrogen-containing volatiles from marine Salinispora pacifica and Roseobacter-group bacteria. J Nat Prod 80:32893295. https://doi.org/10.1021/acs.jnatprod.7b00789

Heiduk A, Kong H, Brake I, von Tschirnhaus M, Tolasch T, Tröger A, Wittenberg E, Francke W, Meve U, Dötterl S (2015) Deceptive Ceropegia dolichophylla fools its kleptoparasitic fly pollinators with exceptional floral scent. Front Ecol Evol 3:66. https ://doi.org/10.3389/fevo.2015.00066

Henning JA, Teuber LR (1992) Combined gas chromatography-electroantennogram characterization of alfalfa floral volatiles recognized by honey bees (Hymenoptera: Apidae). J Econ Entomol 85:226-232. https://doi.org/10.1093/jee/85.1.226

Henning JA, Peng YS, Montague MA, Teuber LR (1992) Honey bee (Hymenoptera: Apidae) behavioral response to primary alfalfa (Rosales: Fabaceae) floral volatiles. J Econ Entomol 85:233239. https://doi.org/10.1093/jee/85.1.233

Holzschuh A, Dudenhöffer JH, Tscharntke T (2012) Landscapes with wild bee habitats enhance pollination, fruit set and yield of sweet cherry. Biol Conserv 153:101-107. https://doi. org/10.1016/j.biocon.2012.04.032

Jackson JE (2003) The biology of apples and pears. University Press, Cambridge

Johnson SD, Hargreaves AL, Brown M (2006) Dark, bitter-tasting nectar functions as a filter of flower visitors in a bird-pollinated plant. Ecology 87:2709-2716. https://doi.org/10.1890/00129658(2006)87\%5b2709:DBNFAA\%5d2.0.CO;2

Joulain D (1987) The composition of the headspace from fragrant flowers: further results. Flavour Fragr J 2:149-155. https://doi. org/10.1002/ffj.2730020403 
Junker RR, Tholl DJ (2013) Volatile organic compound mediated interactions at the plant-microbe interface. Chem Ecol 39:810-825. https ://doi.org/10.1007/s10886-013-0325-9

Jürgens A, Glück U, Aas G, Dötterl S (2014) Diel fragrance pattern correlates with olfactory preferences of diurnal and nocturnal flower visitors in Salix caprea (Salicaceae). Bot J Linn Soc 175:624-640. https://doi.org/10.1111/boj.12183

Khan MR, Khan MR (2004) The role of honey bees Apis mellifera L. (Hymenoptera: Apidae) in pollination of apple. Pak J Biol Sci 7:359-362. https://doi.org/10.3923/pjbs.2004.359.362

Klatt BK, Burmeister C, Westphal C, Tscharntke T, von Fragstein M (2013) Flower volatiles, crop varieties and bee responses. PLoS ONE 8(8):e72724. https://doi.org/10.1371/journal.pone.0072724

Klein AM, Vaissiere BE, Cane JH, Steffan-Dewenter I, Cunningham SA, Kremen C, Tscharntke T (2007) Importance of pollinators in changing landscapes for world crops. Proc R Soc Lond Ser B 274:303313. https://doi.org/10.1098/rspb.2006.3721

Knudsen JT, Eriksson R, Gershenzon J, Ståhl B (2006) Diversity and distribution of floral scent. Bot Rev 72:1-120. https://doi. org/10.1663/0006-8101(2006)72\%5b1:DADOFS\%5d2.0.CO;2

Krug C, Cordeiro G, Schäffler I, Silva CI, Oliveira R, Schlindwein C, Dötterl D, Alves-dos-Santos I (2018) Nocturnal bee pollinators are attracted to guarana flowers by their scents. Front Plant Sci 9:1072. https://doi.org/10.3389/fpls.2018.01072

Loughrin JN, Hamilton-Kemp TR, Andersen RA, Hildebrand DF (1990) Volatiles from flowers of Nicotiana sylvestris, $N$. otophora and Malus $\times$ domestica: headspace components and day/night changes in their relative concentrations. Phytochemistry 29:2473-2477. https ://doi.org/10.1016/0031-9422(90)85169-G

Maccagnani B, Ladurner E, Santi F, Burgio G (2003) Osmia cornuta (Hymenoptera, Megachilidae) as a pollinator of pear (Pyrus communis): fruit-and seed-set. Apidologie 34:207-216. https://doi. org/10.1051/apido:2003009

MacDaniels LH (1940) Morphology of the apple and other pome fruits. Agricultural Experiment Station, Cornell University, Ithaca

Marotz-Clausen G, Jürschik S, Fuchs R, Schäffler I, Sulzer P, Gibernau M, Dötterl S (2018) Incomplete synchrony of inflorescence scent and temperature patterns in Arum maculatum L. (Araceae). Phytochemistry 154:77-84. https://doi.org/10.1016/j.phytochem.2018.07.001

Mas F, Harper A, Horner R, Welsh T, Jaksons P, Suckling DM (2018) The importance of key floral bioactive compounds to honey bees for the detection and attraction of hybrid vegetable crops and increased seed yield. J Sci Food Agric 98:4445-4453. https://doi.org/10.1002/ jsfa.8967

McGregor SE (1976) Insect pollination of cultivated crop plants, vol 496. Agricultural Research Service, US Department of Agriculture, Washington

Milet-Pinheiro P, Ayasse M, Dobson HE, Schlindwein C, Francke W, Dötterl S (2013) The chemical basis of host-plant recognition in a specialized bee pollinator. J Chem Ecol 39:1347-1360. https://doi. org/10.1007/s10886-013-0363-3

Milet-Pinheiro P, Ayasse M, Dötterl S (2015) Visual and olfactory floral cues of Campanula (Campanulaceae) and their significance for host recognition by an oligolectic bee pollinator. PLoS ONE 10(6):e0128577. https://doi.org/10.1371/journal.pone.0128577

Miller RL, Bills DD, Buttery RG (1989) Volatile components from Bartlett and Bradford pear leaves. J Agric Food Chem 37:1476-1479. https://doi.org/10.1021/jf00090a005

Monzón V, Bosch J, Retana J (2004) Foraging behavior and pollinating effectiveness of Osmia cornuta (Hymenoptera: Megachilidae) and Apis mellifera (Hymenoptera: Apidae) on" Comice" pear. Apidologie 35:575-585. https://doi.org/10.1051/apido:2004055

Oekolandbau (2015) Ökologischer Birnenanbau. http://www.oekolandba u.de/landwirtschaft/pflanze/ spezieller-pflanzenbau/obstbau/birnen/. Accessed 28 Aug 2019
Oliveira PE, Tomé CER, Torezan-Silingardi HM, Dötterl S, SilberbauerGottsberger I, Gottsberger G (2017) Differential pollination modes between distant populations of Unonopsis guatterioides (Annonaceae) in Minas Gerais and Amazonas, Brazil. Flora 232:39-46. https://doi.org/10.1016/j.flora.2016.07.014

Ollerton J, Winfree R, Tarrant S (2011) How many flowering plants are pollinated by animals? Oikos 120:321-326. https://doi.org/10.111 1/j.1600-0706.2010.18644.x

Ômura H, Honda K (2005) Priority of color over scent during flower visitation by adult Vanessa indica butterflies. Oecologia 142:588-596. https://doi.org/10.1007/s00442-004-1761-6

Rader R, Bartomeus I, Garibaldi LA, Garratt MP, Howlett BG, Winfree R, Cunningham SA, Mayfield MM, Arthur AD, Andersson GKS, Bommarco R, Brittain C, Carvalheiro LG, Chacoff NP, Entling MH, Foully B, Freitas BM, Gemmill-Herren B, Ghazoul J, Griffin SR, Gross CL, Herbertsson L, Herzog F, Hipólito H, Jaggar S, Jauker F, Klein AM, Kleijn D, Krishnan S, Lemos CQ, Lindström SAM, Mandelik Y, Monteiro VM, Nelson W, Nilsson L, Pattemore DE, de O. Pereira N, Pisanty G, Potts SG, Reemer M, Rundlöf M, Sheffield CS, Scheper J, Schüepp C, Smith HG, Stanley DA, Stout JC, Szentgyörgyi H, Taki H, Vergara CH, Viana BF, Woyciechowski M (2016) Non-bee insects are important contributors to global crop pollination. Proc Natl Acad Sci U S A 113:146-151. https://doi. org/10.1073/pnas.1517092112

Raguso RA (2008) Wake up and smell the roses: the ecology and evolution of floral scent. Annu Rev Ecol Evol Syst 39:549-569. https:// doi.org/10.1146/annurev.ecolsys.38.091206.095601

Schäffler I, Steiner KE, Haid M, Van Berkel SS, Gerlach G, Johnson SD, Wessjohann L, Dötterl S (2015) Diacetin, a reliable cue and private communication channel in a specialized pollination system. Sci Rep 5:12779. https://doi.org/10.1038/srep12779

Schanderl H (1937) Befruchtungsbiologische Studien an Birnen. Die Gartenbauwissenschaft 11:297-318

Schiestl FP, Marion-Poll F (2002) Detection of physiologically active flower volatiles using gas chromatography coupled with electroantennography. In: Jackson JF, Linskens HF, Inman RB (eds) Analysis of taste and aroma. Molecular methods of plant analysis, vol 21. Springer, Berlin, pp 173-198. https://doi.org/10.1007/978-3-662-04857-3_9

Schumacher R (1989) Die Fruchtbarkeit der Obstgehölze. Eugen Ulmer Verlag, Stuttgart

Shipp JL, Whitfield GH, Papadopoulos AP (1994) Effectiveness of the bumble bee, Bombus impatiens Cr. (Hymenoptera: Apidae), as a pollinator of greenhouse sweet pepper. Sci Hortic (Amst, Neth) 57:29-39. https://doi.org/10.1016/0304-4238(94)90032-9

Stephen WP (1958) Pear pollination studies in Oregon. Technical bulletin 43, Bull Ore Agric Exp Stn, Corvallis

Thiery D, Bluet JM, Pham-Delègue MH, Etiévant P, Masson C (1990) Sunflower aroma detection by the honeybee. J Chem Ecol 16:701711. https://doi.org/10.1007/BF01016481

Wadhams LJ, Blight MM, Kerguelen V, Le Métayer M, Marion-Poll F, Masson C, Pham-Delègue MH, Woodcock CM (1994) Discrimination of oilseed rape volatiles by honey bee: novel combined gas chromatographic-electrophysiological behavioral assay. J Chem Ecol 20:3221-3231. https://doi.org/10.1007/BF02033722

WAPA Association (2019) The world apple and pear association. http:// www.wapa-association.org. Accessed 20 Aug 2019

Williams IH (1994) The dependence of crop production within the European Union on pollination by honey bees. Agric Zool Rev (U K) 6:229-257

Williams IH, Pickett JA, Martin AP (1982) Nasonov pheromone of the honeybee Apis mellifera L. (Hymenoptera, Apidae). J Chem Ecol 8:567-574. https://doi.org/10.1007/BF01402919

Zito P, Dötterl S, Sajeva M (2015) Floral volatiles in a sapromyiophilous plant and their importance in attracting house fly pollinators. J Chem Ecol 41:340-344. https://doi.org/10.1007/s10886-015-0568-8 